\title{
A relative study to illustrate the infection control practices based on knowledge, attitude and practices at a tertiary university hospital
}

\begin{abstract}
Background: For better planning, hospital infection control supervisors should be aware of the behavioral status of their employees. The aim of this study was to evaluate the knowledge, attitude and practice of nurses and physicians in the field of infection control at a tertiary university hospital in north-eastern Iran.
\end{abstract}

Methods: In this prospective cohort study, a researcher based questionnaire was used to assess the knowledge and attitude of the participants. Additionally, a checklist completed by several trained observers, was used to evaluate their practice, based on the opportunities and overall performance of the subjects.

Results: Totally 334 people (including 180 nurses and 154 physicians) were evaluated. Only $1.5 \%$ of respondents had low knowledge level. There was no significant difference between the knowledge level of physicians and nurses $(p=0.101)$. Also, $97.7 \%$ of subjects had a positive attitude towards infection control issues. In general, poor practice was only detected in $8.7 \%$ of the participants. Nevertheless, in issues such as hand hygiene upon entering the ward, removing rings or watches during hand washing and hand washing with soap and water for $15-30$ seconds, less than $20 \%$ of them had proper performance.

Conclusion: The present study demonstrated that the knowledge and attitude of physicians and nurses towards infection control issues in hospital seem acceptable. However, the percentage of poor practice compared with attitude and knowledge was higher. Despite overall favorable practice, the participants' performance was poor with respect to certain important issues that deserve special attention.

Keywords: nosocomial infection, infection control, knowledge, attitude, practice
Volume 4 Issue 3 - 2017

\author{
Hamid Reza Naderi,' Fereshte Sheybani,' \\ Rozita Khodashahi,' Mehdi Jabbari \\ Nooghabi ${ }^{2}$ \\ 'Department of Infectious Diseases, Mashhad University of \\ Medical Sciences, Iran \\ ${ }^{2}$ Department of Statistics, Ferdowsi University of Mashhad, Iran
}

Correspondence: Sheybani F, Department of Infectious Diseases, Imam Reza Hospital, Daneshgah Ave, Ibne Sina Street, Imam Reza Hospital, Mashhad, Iran, Tel 9151254062,

Email sheybanif@musms.ac.ir, fereshtesheybani@gmail.com

Received: February 08, 2017 | Published: March 17, 2017

\section{Background}

Approximately 5 to $10 \%$ of patients admitted to acute-care hospitals or 2 million patients per year in the United States acquire a nosocomial infection. ${ }^{1}$ Of these, 50 to $70 \%$ are caused by antimicrobialresistant strains of bacteria and 77,000 to 90,000 infected patients die annually. ${ }^{2}$ The World Health Organization has reported that, at any given time, approximately 1.4 million people have a healthcareassociated infection. ${ }^{3}$ Furthermore, the annual economic impact of these infections in the United States was estimated to be US $\$ 6.5$ billion. ${ }^{4}$

The rate of infection is higher in developing countries and annually about 2 to 4 million cases of nosocomial infection occur in these countries, so that it is the eleventh leading cause of death in the world and the fifth leading cause of death in hospitals. ${ }^{5}$ The prevalence of this kind of infections in Iran has been reported between $1.9 \%$ and $25 \%{ }^{6}$ The main goal of infection control program is reducing the risk of hospital-acquired infections to protect the patients, hospital staff and visitors.

In order to achieve this goal, an organization has been established which is called Hospital Infection Control Committee (HICC). HICC is responsible for planning and evaluation of all the matters relating to infection control. One of the main tasks of HICC is to program education, and in this regard, infection control nurse plays a key role in the implementation of educational programs. The most fundamental issue of conforming to health standards is, knowledge or ignorance, agreement or disagreement and respecting or disrespecting the rules. Therefore, being aware of the health behavior is one of the basic issues. ${ }^{7}$ Preventing nosocomial infections requires consideration of three concepts of knowledge, attitude and practice. Since in developing a training program, scrutiny of knowledge and attitude level and performance quality is considered as the first step, awareness of the beliefs and behavior of hospital staff, especially nurses, about the key points of infection control is of particular importance. Considering these facts, we decided to assess the knowledge, attitude and practice of physicians and nurses in the field of hospital infection control at Imam Reza Hospital which is a reference hospital in the north-eastern Iran.

\section{Method}

The present study is a prospective cohort study that was conducted during the period of 6 months, from February to August 2015. In this study, the sample size was selected using the probability sampling technique and by stratified sampling method. According to the research purpose, to explore the hypotheses and research questions, primary chi-square test was used. By considering the low power of $80 \%$ for this experiment and a significance level of $5 \%$, the minimum sample size of 334 was calculated for the study which must be divided into two groups based on the number of the nurses and physicians. Samples of each group were randomly selected. Software such as NCSS \& PASS was used in order to estimate the sample size. Data were collected by questionnaire. Participation of all the subjects was 
based on personal consent and they were assured of the confidentiality of the personal information. The hospital was the location of the project including all the intensive care units, internal medicine, pediatrics, surgery, gynecology and emergency departments.

Questionnaires were set in two sections, the first section was related to data and personal information including gender, occupation, years in service and the work units, and the second part contained three separate sheets:

i. Questions related to knowledge included 9 which were evaluated based on "yes or no" answers.

ii. Questions related to the attitude consisted of 8. The scale used to determine the level of attitude was from 0 to 10 for any questions.

iii. Questions related to the practice were 16 . The behavior included issues regarding hand washing, maintaining the standard precautions when dealing with patients and caring activities and disposal of hospital waste. Information on the performance was evaluated by supervision of executive assistant and three trained nurses of HICC by presence in different hospital departments and observing the practice of subjects to evaluate opportunities which were recorded on the questionnaire. Considering the diversity of observers, as well as the difficulty of identifying "opportunity", in which proper practice should be performed, the Inter Rater Reliability method was used to measure the reliability of the performance questionnaire. The homogeneity of measurements which were done with one tool on set of single subjects by three assessors was calculated to check the degree of assessors' agreement on the tool. In order to assess the reliability of this method, intra-class correlation was used.

The total score of attitude could be in the range of 0 to 80 . If the answers to the knowledge questions were correct, then score one was assigned, otherwise a zero score was considered. The sum of scores for these issues ranged from 0 to 9 . Questions relating to the practice according to the "Yes or No" answer, would be given zero or one, and the total score would be in the range of 0 to 16 .

The final score, which was obtained from the total scores of each group of questions related to a domain, was classified in a way that top one-third scores indicated an excellent knowledge, attitude, and practice. The middle third scores indicated an average level, and the lower one-third showed a poor knowledge, attitude, and poor practice.

\section{Results}

This study was conducted on 334 hospital staff, 18 (53.9\%) nurses and $154(46.1 \%)$ physicians. Overall, $210(62.9 \%)$ were female and $124(37.1 \%)$ were male. Comparing genders in both groups showed a significant difference between the two groups based on the job, so that $68.3 \%$ of the nurses and $56.5 \%$ of the physicians were female. The mean age of the population study was $35.3 \pm 7.22$ years, in the range of 25 to 55 years. Regarding the location of employment, most of the subjects were working in the internal medicine (19.5\%), surgery $(17.7 \%)$ and emergency $(13.5 \%)$ departments. The statistical comparison showed that the two occupational groups were not statistically different from each other based on the location ( $\mathrm{p}=0.902)$. The average work experience of the subjects was $9.4 \pm 6.08$ years, in the range of 0 to 28 years. Additionally, two occupational groups were being compared regarding their average years of work experience which indicated that the nurses had more job experience than the physicians and the difference was significant (Table 1).

Knowledge of subjects was assessed using 9 questions. So, based on the number of correct answers, people could obtain a score in the range of 0 to 9 . The average score of $6.5 \pm 1.863$ was obtained by the participants. The results showed that the average score was higher in the physician group, but the difference was not statistically significant (Table 1).

Table I Years in service, knowledge and attitude scores and percentage of actual practices in related to occupation of respondents [Mann-Whitney test].

\begin{tabular}{|c|c|c|c|c|c|c|c|}
\hline Maximum & Minimum & SD & Median & Mean & Number & & Occupation \\
\hline 28 & 2 & 6.33 & 12 & 12.8 & Years in Service & \multirow{4}{*}{180} & \multirow{4}{*}{ Nurse } \\
\hline 9 & 2 & 1.876 & 6 & 6.34 & Knowledge & & \\
\hline 80 & 40 & 7.63 & 76 & 73.3 & Attitude & & \\
\hline 90.9 & 0 & 18.9 & 60 & 53.7 & Practice (\%) & & \\
\hline 20 & 0 & 4.97 & 3.5 & 5.5 & Years in service & \multirow{4}{*}{154} & \multirow{4}{*}{ Physician } \\
\hline 9 & 2 & $\mathrm{I} .834$ & 7 & 6.69 & Knowledge & & \\
\hline 79 & 52 & 4.77 & 71 & 70 & Attitude & & \\
\hline 100 & 0 & 16.42 & 60 & 59.3 & Practice (\%) & & \\
\hline 28 & 0 & 6.8 & 9 & 9.4 & Years in service & \multirow{4}{*}{334} & \multirow{4}{*}{ Total } \\
\hline 9 & 2 & $\mathrm{I} .863$ & 6.5 & 6.5 & Knowledge & & \\
\hline 80 & 40 & 6.67 & 72 & 71.8 & Attitude & & \\
\hline 100 & 0 & 17.8 & 60 & 58.2 & Practice (\%) & & \\
\hline
\end{tabular}

Years in Service: $p<0.001$; Knowledge: $p=0.101$; Attitude: $p<0.001$; Practice: $p=0.319$

By dividing the level of knowledge on the basis of scores as high (score 7 or higher), moderate (score 6-3) and low (score less than 3) it was found that generally $48.5 \%$ of individuals had an average level of knowledge and $50 \%$ had a high knowledge level. Comparing the two groups in terms of knowledge showed that the two groups were not statistically different in this respect (Table 2).

To assess attitude, 8 questions were used and the subjects were asked to score each sentence from 0 to 10 based on their degree of agreement (higher score meant more agreement with the sentence). The average score was $71.8 \pm 6.67$. Comparing scores in two occupational groups showed that nurses on average gave higher scores than physicians $(73.3 \pm 7.63$ compare with $70 \pm 4.77)$ which was significant $(\mathrm{p}<0.001)$ (Table 1). By dividing total scores of participants on attitude, 3 levels of attitude were obtained as follows: positive attitude (grades 80-54), neutral (grades 53-28) and negative (Grades 27-0). It was found the majority of participants $(97.7 \%)$ have a positive attitude towards the proposed issues. 
Comparing the attitudes of the two occupational groups showed no significant difference in this respect between the two groups (Table 2 ). In order to evaluate the practice, 16 positions were considered. Subjects were observed in each opportunity and their performance was assessed. Accordingly, participants had proper practice $58.2 \pm 17.80$ percent of the time. Comparison between the two occupational groups showed that although the prevalence of proper practice among physicians was higher, the difference is not significant between the two groups (Table 1). The performance of participants was divided into poor practice (correct performance at less than $33 \%$ of opportunities), moderate (correct performance at $66-34 \%$ of the opportunities) and good practice (best performance in more than $66 \%$ of the times). It was found that $8.7 \%$ of participants had poor practice, $54.5 \%$ of them average and $36.8 \%$ of subjects had good practice. Comparison of nurses and physicians revealed no significant difference between the two groups in this respect (Table 2).

Also, it was found that there is no correlation between work experience and score of knowledge and attitude of physicians and nurses. Table 3 shows this comparison. Finally, the percentages of good practice for nurses and physicians were assessed in each of 16 opportunities. The comparison between two groups in terms of occupation also showed that they were not significantly different (Figure 1).

Table 2 Comparison of knowledge, attitude and actual practice level of respondents in related to years in service and occupation [Fisher's exact test]

\begin{tabular}{|c|c|c|c|c|c|}
\hline & Nurse & Physician & Total & $P$ value & \\
\hline Years of service (mean) & & $12.8 \pm 6.33$ & $5.5 \pm 4.97$ & $9.4 \pm 6.8$ & $\mathrm{p}<0.00 \mathrm{I}$ \\
\hline Knowledge score & & $6.3 \pm 1.88$ & $6.7 \pm 1.83$ & $6.5 \pm 1.86$ & $p=0.101$ \\
\hline Knowledge level & Low & $4(2.2)$ & I (0.6) & $5(1.5)$ & \\
\hline \multirow[t]{2}{*}{ NO. (\%) } & Moderate & $94(52.2)$ & $68(44.2)$ & $162(48.5)$ & $p=0.157$ \\
\hline & High & $82(45.6)$ & $85(55.2)$ & $167(50)$ & \\
\hline Attitude score & & $73.3 \pm 7.63$ & $70 \pm 4.77$ & $71.8 \pm 6.67$ & $\mathrm{p}<0.00 \mathrm{I}$ \\
\hline Attitude level & Negative & 0 & 0 & 0 & \\
\hline \multirow[t]{2}{*}{ NO. (\%) } & Neutral & $5(2.8)$ & $2(1.3)$ & $7(2.1)$ & $p=0.458$ \\
\hline & Positive & 175 (97.2) & 152 (98.7) & 327 (97.9) & \\
\hline Actual practices & & $57.3 \pm 18.9$ & $59.3 \pm 16.42$ & $58.2 \pm 17.8$ & $p=0.319$ \\
\hline Practice level & Poor & $17(9.4)$ & $12(7.8)$ & $29(8.7)$ & \\
\hline \multirow[t]{2}{*}{ NO. (\%) } & Moderate & $96(53.3)$ & $86(55.8)$ & $182(54.5)$ & $p=0.963$ \\
\hline & Good & $67(37.2)$ & $56(36.4)$ & $123(36.8)$ & \\
\hline
\end{tabular}

Table 3 Comparison of knowledge and attitude scores in related to years in service of respondents [Kruskal-Wallis test]

\begin{tabular}{|c|c|c|c|c|c|c|c|}
\hline \multirow[t]{3}{*}{ Occupation } & \multicolumn{3}{|c|}{ Years in ServiceNumber } & \multirow{2}{*}{$\begin{array}{l}\text { Mean } \\
6.9\end{array}$} & \multirow{2}{*}{$\begin{array}{l}\text { Median } \\
8\end{array}$} & \multirow{2}{*}{$\begin{array}{l}\text { SD } \\
1.88\end{array}$} & \multirow{2}{*}{$\begin{array}{l}\text { P value } \\
p=0.274\end{array}$} \\
\hline & $<5$ yอorc & 10 & Knowledge & & & & \\
\hline & o years & 17 & Attitude & 71.6 & 73 & 6.91 & $p=0.113$ \\
\hline \multirow{6}{*}{ Nurse } & \multirow{2}{*}{$5-15$ years } & \multirow{2}{*}{109} & Knowledge & 6.2 & 6 & 1.95 & $p=0.274$ \\
\hline & & & Attitude & 73.6 & 77 & 8.42 & $p=0.113$ \\
\hline & \multirow{2}{*}{$>15$ years } & \multirow{2}{*}{52} & Knowledge & 6.5 & 6 & 1.67 & $p=0.274$ \\
\hline & & & Attitude & 73.5 & 75.5 & 5.99 & $p=0.113$ \\
\hline & \multirow{2}{*}{$<5$ years } & \multirow{2}{*}{88} & Knowledge & 6.8 & 7 & 1.77 & $p=0.104$ \\
\hline & & & Attitude & 69.8 & 71 & 4.87 & $p=0.870$ \\
\hline \multirow{4}{*}{ Physician } & \multirow{2}{*}{$5-15$ years } & \multirow{2}{*}{62} & Knowledge & 6.4 & 6.5 & 1.9 & $p=0.104$ \\
\hline & & & Attitude & 70.3 & 71 & 4.77 & $p=0.870$ \\
\hline & \multirow{2}{*}{$>15$ years } & \multirow{2}{*}{4} & Knowledge & 8 & 8.5 & $1.4 \mathrm{I}$ & $p=0.104$ \\
\hline & & & Attitude & 7I & 70 & 2.71 & $p=0.870$ \\
\hline
\end{tabular}

\section{Discussion}

The results of this study showed that the mean score in knowledge of infection control among physicians and nurses was acceptable and the subjects on average, obtained more than $70 \%$ of the score $(6.5$ of the total score of 9). "Hand washing is one of the pillars of standard precautions" gained the highest percentage of correct answers, while "Hospital environment is a facilitator of transmitting infection" and "The hospital staff is a potential risk for transmission of infection to patients" scored the lowest percentages.

Obviously, the low percentage of correct answers for these two issues show that the important role of the hospital environment and staff in infection control is still not well understood by staff. Previous studies in this field in Iran mainly focused on nurses. According to Ghadamgahi and colleagues ${ }^{8}$ study on nursing staffs at some hospitals in Mashhad, only $2.2 \%$ of subjects had low knowledge level about hospital infection control and most had an average or good level of knowledge. ${ }^{8}$ Amerioun and colleagues ${ }^{9}$ in their study also showed that $65 \%$ of nurses had good knowledge in the field of infection control. ${ }^{9}$ Similarly, a study conducted by Parmeggiani et al. ${ }^{10}$ demonstrated that most of the nurses in the field of healthcare practice have a high level of knowledge about standard precautions. ${ }^{10}$ In contrast, Abdullahi and colleagues ${ }^{11}$ showed that $26.5 \%$ of nurses out of 518 subjects had very low level of knowledge with respect to infection control measures. ${ }^{11}$ Kamulegeya et al. ${ }^{12}$ also found that $51.4 \%$ of nurses out of 209 participants have poor or wrong knowledge about the transmission of blood-borne organisms. ${ }^{12}$ In the study by Darawad and colleagues ${ }^{13}$ 
which evaluated 198 nurses, it was also shown that Jordanian nurses have moderate level of compliance with hand-washing and poor knowledge about hand hygiene protocols. ${ }^{13}$ These observed differences may be due, to some extent, to the use of different tools (different questionnaires) in the cited studies. Because of the difference in the content, design and difficulty of the questions (multiple choices vs. yes/no answers) various classification of knowledge in different studies makes it impossible to compare them accurately.

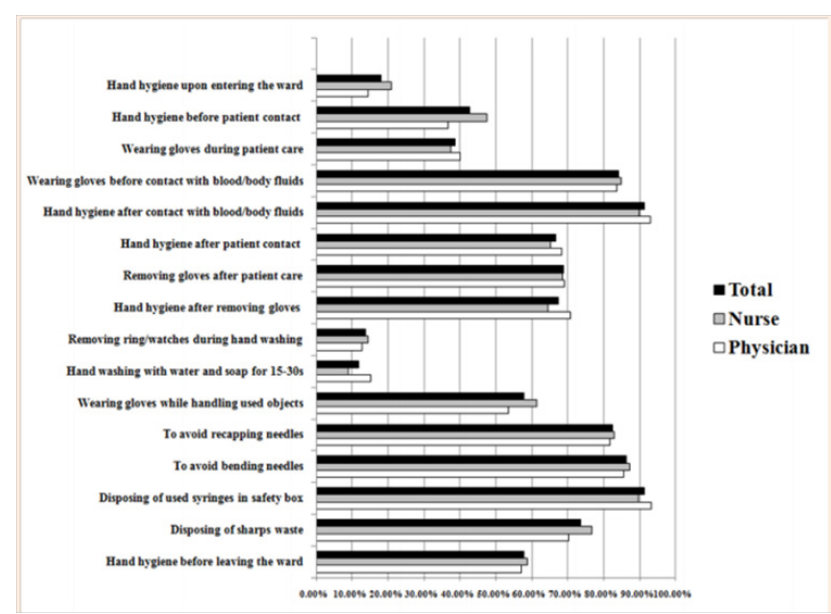

Figure I Percentage of good practice in different opportunities in related to occupation.

With respect to attitude, participants of the present study gained higher scores on average (72 score out of 80 ), which represents that most personnel $(95 \%)$ showed a positive attitude towards infection control believes. It was noted that the scores of nurses were significantly higher than physicians. The findings of this study are consistent with other studies in this area. The study by Ghadamgahi ${ }^{8}$ also showed that the majority of personnel understood the threats and had a positive attitude towards hospital infection prevention methods. ${ }^{8}$ Allahbakhshian and Karimi's ${ }^{14,15}$ studies showed similar results and the study by Parmeggiani et al. ${ }^{10}$ also demonstrated most of the healthcare workers $(94 \%)$ had a positive attitude towards infection control programs. ${ }^{10}$

McGaw et al. ${ }^{16}$ studied the difference between the attitudes of nurses and physicians with respect to the infection control guidelines in surgical wards. In this study, 90 physicians and 42 nurses who constituted $73 \%$ and $75 \%$ of the total staff were assessed. They concluded that nurses generally had higher positive attitude $(\mathrm{p}<0.001)$ and higher acceptance rate $(\mathrm{p}=0.008)$ compared with the physicians. ${ }^{16}$ Stein and colleagues also run an experiment on 75 physicians and 143 nurses in whom the results showed that physicians significantly had weaker outlook and attitude in that matter. Also, physicians and nurses had significant difference with regard to attitude and compliance of hand washing before and after contacting a patient and wearing gloves when taking blood ( $p<0.001$ for all). ${ }^{17}$ The positive attitude is mainly coming from adequate and accurate knowledge in the relevant field. As was shown in the present study, the attitude and knowledge levels were higher among the nurses. Although there is a thin line between knowledge and attitude, raising the level of knowledge generally leads to positive attitude. Continuous education can change people's attitudes, so that key points turn to a principle. Regarding the practice, participants of the study on average had a proper performance in $58.2 \%$ of the times. Comparison of the two occupational groups showed that despite the fact that there was a higher percentage of good practice among physicians; the difference between the two groups was not significant. As demonstrated, the percentage of poor practice was higher and the mean of good performance compared with percentage of correct answers and positive attitude among the subjects was lower. These findings were consistent with Askarian $^{18}$ \& Parmeggiani ${ }^{10}$ results. In their studies, they showed that despite having a high level of knowledge and positive attitude towards infection control and standard precautions, the performance of the individuals was poor. Different reasons are discussed and the most important of them can be traced to the influence of high workload. ${ }^{19}$ Too few staff, too many patients will reduce the quality of health care. The long work shifts due to labor shortage can also lead to fatigue and inattention to infection control principles. Other influential factors can be pointed to a lack of resources for standard precautions. ${ }^{19}$ To achieve the proper behavior, infection control principles should be internalized and should appear in the mental functions of individual staff, which means that raising the level of knowledge upgrades attitudes and ultimately leads to good practice. In this regard, Foster and his colleagues conducted a study to assess the knowledge, acceptance and practice of health professionals (physicians and nurses) in the field of workplace infection control which showed despite the fact that health personnel were aware of the infection risks, they had lower adherence to standard precautions. ${ }^{20} \mathrm{In}$ the present study issues such as " 15 to 30 seconds of hand washing with soap and water" (12\%), "removing rings or watches while washing hands"(14\%)," hand hygiene upon entering the ward" $(18 \%)$," wearing gloves during patient care "(39\%) and "hand hygiene before patient contact" $(43 \%)$ had the lowest percentage of proper performance. One of the major reasons behind the staff's poor practice in hospital infection control activities can be lack of belief on the usefulness of these activities.

According to the study by Kennedy and colleagues ${ }^{21}$ on 215 workers in the neonatal intensive care unit (NICU), only $35 \%$ of the participants were aware that the amount of bacteria on the surface of a hand wearing a ring is higher, and only $30 \%$ and $35 \%$ of them knew that long nails and artificial nails are associated with higher pollution of gram-negative bacteria, respectively. $61 \%$ of subjects wore at least one ring while working and $8 \%$ of them used artificial nails. They concluded that there is a disconnect between knowledge, attitude and practice in the field of hospital infection control principles. Health service staffs were not properly aware that there is a relationship between wearing a ring and bacteria count on hands. Also, they did not believe that ring, long or artificial fingernails increase the risk of nosocomial infections. ${ }^{21}$ In summary, the literature also notes that despite the proper overall performance of the workplace staff, it seems insufficient in some key issues that are very effective in the transmission of hospital germs.

\section{Conclusion}

Despite the proven effects of infection control activities, personnel providing health care sometimes have low knowledge level and poor practice in dealing with patients which leads to failure in infection control programs. This study showed that the knowledge and positive attitude towards standard precautions and infection control programs of hospital staff is at an acceptable level. Nonetheless, the percentage of poor practice in relation to attitude and knowledge is higher. Therefore, continuous training and regular monitoring seem to be necessary in order to solve these issues.

\section{Conflict of Interest}

The authors declare no conflict of interest. 


\section{Acknowledgments}

None.

\section{Funding}

None.

\section{References}

1. Sydnor ERM, Perl TM. Hospital Epidemiology and Infection Control in Acute-Care Settings. Clin Microbiol Rev. 2011;24(1): 141-173.

2. Mauldin PD, Salgado CD, Hansen IS, et al. Attributable hospital cost and length of stay associated with health care-associated infections caused by antibiotic-resistant gram-negative bacteria. Antimicrob Agents Chemother. 2010;54(1):109-115.

3. Cardo D, Dennehy PH, Halverson P, et al. Moving toward elimination of healthcare-associated infections: A call to action. Infect Control Hosp Epidemiol. 2010;31(11):1101-1105.

4. Stone PW, Braccia D, Larson E. Systematic review of economic analyses of health care-associated infections. Am J Infect Control. 2005;33(9):501-509.

5. Hasanabadi S, Majidpor A, Habibzadeh SH. Create open and emerging diseases and professionals health at health worker. Department of Health and Medical Education Publication, Tehran, Iran. 2009.

6. Sohrabi M. Incidence of nosocomial infections in Imam Hussein hospital, Shahrood. Brigands Uni Med Sci J. 2009;16(3):33-39.

7. Mohseni M. Foundations of health education. Tehran Publications, Tehran, Iran. 2002.

8. Ghadamgahi F, Zighaimat F, Ebadi A, et al. A Knowledge, attitude and self-efficacy of nursing staffs in hospital infections control. J Mil Med. 2011;13(3):167-172.

9. Amerioun A, Karimi Zarchi AA, et al. Supervisors' knowledge of hospital infections control in one of the medical sciences university's related hospitals. J Mil Med. 2009;11(2):97-101.

10. Parmeggiani C, Abbate R, Marinelli P, et al. Healthcare workers and health care-associated infections: knowledge, attitudes, and behavior in emergency departments in Italy. BMC Infect Dis. 2010;10:1-35.
11. Abdollahi AA, Rahmani H, Khodabakhshi B, et al. Assessment of level of knowledge, attitude and practice of employed nurses to nosocomial infection in teaching hospitals of Golestan University of Medical Sciences . J Gorgan Uni Med Sci. 2003;5(1): 80-86.

12. Kamulegeya A, Nninda Kizito A, Balidawa H. Ugandan medical and health sciences interns' infection control knowledge and practices. $J$ Infect Dev Ctries. 2013;7(10):726-733.

13. Darawad MW, Al Hussami M, Almhairat II, et al. Investigating Jordanian nurses' handwashing beliefs, attitudes, and compliance. Am J Infect Control. 2012;40(7):643-647.

14. Alahbakhshian A, Moghadasian S, Zamanzadeh V. Knowledge attitude and practice health care in intensive care at Tabriz hospital. Iran Nurs $J$. 2009;23(64):17-27.

15. Karimi SH, KHademian M. A survey on knowledge attitude and practice of medical staff to pathogen factor with blood at Shariati hospital in Fasa. Iranian Congress of Infections Disease, Tehran, Iran. 2001.

16. McGaw CD, Tennant I, Harding HE, et al. Healthcare workers' attitudes to and compliance with infection control guidelines in the operating department at the university hospital of the West Indies, Jamaica. Int $J$ Infect Control. 2012;8(3):1-9.

17. Stein AD, Makarawo TP, Ahmad MF. A survey of doctors' and nurses' knowledge, attitudes and compliance with infection control guidelines in Birmingham teaching hospitals. J Hosp Infect. 2003;54(1):68-73.

18. Askarian M, Memish ZA, Khan AA. Knowledge, practice, and attitude among Iranian nurses, midwives, and students regarding standard isolation precautions. Infect Control Hosp Epidemiol. 2007;28(2):241244.

19. Kilpatrick C, Allegranzi B, Pittet D. WHO First Global Patient Safety Challenge: Clean Care is Safer Care. Contributing to the training of health-care workers around the globe. Int J Infect Control. 2009;7(2): $1-8$.

20. Foster TM, Lee MG, McGaw CD, et al. Knowledge and practice of occupational infection control among healthcare workers in Jamaica. West Indian Med J. 2010;59(2):147-152.

21. Kennedy AM, Elward AM, Fraser VJ. Survey of knowledge, beliefs, and practices of neonatal intensive care unit healthcare workers regarding nosocomial infections, central venous catheter care, and hand hygiene. Infect Control Hosp Epidemiol. 2004;25(9):747-752. 